\section{Re: Advertisements}

As we have pointed out previously, we accept advertisements that are compatible with the RCGP's Advertising Guidelines, and expect readers to exercise their own critical faculties, as $\mathrm{Dr}$ Ashworth has done here - Ed.

DOI: 10.3399/bjgp08X279887

\section{Appraisals}

Conlon concludes in his editorial on regulation ${ }^{1}$ that GPs need to make a personal choice between independent and interdependent practice, but this seems a false dichotomy. Most GPs are both independent in the sense of practising unsupervised, and interdependent in that they work with, and are supported by, other professionals and GP colleagues, particularly in practice teams.

His vision of a supportive organisation, in which doctors welcome performance measurement and scrutiny as ways of understanding and improving their work, is attractive. Unfortunately, given the lack of understanding and appreciation of the roles and efforts of doctors shown by Government and the Department of Health over the last two decades, the NHS is unlikely to become such an organisation.

Besides, it is still questionable whether it is possible to develop measures of GP performance which are meaningful and useful enough to justify the costs, especially in doctor time, of their development and application. However good the measures, making them part of the appraisal in today's NHS would risk undermining appraisal's supportive and developmental role, and reducing the number of GPs who value it to even less than the disappointing $40 \%$ reported by Colthart, et $a /^{2}$ in the same issue of the Journal.

\section{John Temple}

GP appraiser, 74 Park Road,

Chilwell, Nottingham NG9 4DD.

E-mail: John.Temple@nottingham.ac.uk

\section{REFERENCES}

1. Conlon M. Regulation: appraisal alone is not enough. Br J Gen Pract 2008; 58(547): 80-81.

2. Colthart I, Cameron N, McKinstry B, Blaney D. What do doctors really think about the relevance and impact of GP appraisal 3 years on? A survey of Scottish GPs. Br J Gen Pract 2008; 58(547): 82-87.

DOI: 10.3399/bjgp08X279896

\section{Management of headache}

In response to Kernick, et al's' article I would like to describe my approach to primary headache. In the 1980s my husband, then a medical registrar, would regularly spend Mondays after weekends on call in bed with a prostrating symmetrical headache accompanied by vomiting. During my first pregnancy he came with me as a dutiful father-to-be to relaxation classes. The relaxation techniques we learnt and practised were invaluable to me in labour. The unexpected outcome was that my husband's headaches resolved. It is debatable whether they were tension headaches, or migraine without aura. According to Goadsby $^{2}$ classification is still controversial. However, many headaches in primary care fall in this uncertain category.

When patients present with tension headache I encourage them to think about muscular relaxation particularly of the muscles around the head, neck and shoulders. I explain that the scalp is covered by a layer of muscle like a swimming cap, which connects with the face, the jaw, the back of the neck and shoulders, and that tightness in these muscles may produce pain as in any clenched muscle. Often examination reveals tenderness at the temples or occiput or in the neck extensors, which illustrates the point. I encourage the patient to become aware of frowning, or raising the eyebrows, or clenching the jaw, and to focus on relaxing these muscles.

This explanation might be simplified or inaccurate as pathophysiology, but there are benefits of a clear diagnosis and explanation. First, if patients fear brain tumour, it is much more satisfactory to have a definite diagnosis than to be told 'nothing is wrong'. Second, some patients resent the label of tension headache for its psychological implications. Often, patients with tension headache do have anxiety or depression which may be rewarding to explore, but others say, 'I'm not tense!' Here it is helpful to discuss muscular relaxation.

I note in BMJ Clinical Evidence on tension headache ${ }^{3}$ that relaxation is mentioned, but is described as timeconsuming to apply. I would dispute this. I think the principle can be explained quite quickly, and patients can be referred to self-help materials and relaxation tapes. Some women remember being taught relaxation at antenatal classes.

I also encourage patients to look for precipitants and trigger factors. The pathophysiology of these, and whether they apply to migraine without aura or tension headaches is again not clear to me, but pragmatically the following list is worth considering, and patients often notice something they had not previously thought of:

- caffeine, chocolate, cheese, citrus fruits and juices, onion, raw apple, alcohol; also

- fatigue, lack of fluid intake, or missed meals.

I note that Goadsby' says, 'so much good can be done for migraine sufferers and so little for tension-type headache'. This impression may well be behind GPs' difficulties. I suspect the lack of research into tension headache reflects the lack of pharmaceutical prospects. I would be interested to know how other GPs approach this problem.

\section{Alison Jackson}

GP, Green Lane Medical Centre, Coventry. E-mail: alison.jackson@nhs.net

\section{REFERENCES}

1. Kernick D, Stapley S, Hamilton W. GPs' classification of headache: is primary headache underdiagnosed? Br J Gen Pract 2008; 58(547): 102-104.

2. Goadsby PI. Headache. In: Warrell D, Cox TM, Firth JD, Benz EJ (eds). Oxford textbook of medicine. Oxford: University Press, 2004. 